\title{
LONG-TERM RESULTS OF SIMULTANEOUS CAROTID ENDARTERECTOMY AND MYOCARDIAL REVASCULARIZATION WITH CARDIOPULMONARY BYPASS USED FOR BOTH PROCEDURES
}

Kazutomo Minami, MD, PhD

Kazuaki Fukahara, MD

Dietmar Boethig, MD

Andreas Bairaktaris, MD

Dirk Fritzsche, MD, PhD

Reiner Koerfer, MD, PhD
Objective: Controversy continues about the treatment of patients with a concomitant occlusive disease of the coronary and carotid arteries. Our operative strategy in these patients is to do simultaneous carotid endarterectomy and myocardial revascularization in conjunction with cardiopulmonary bypass with mild hypothermia. We report our experience with this kind of one-stage procedure and its retrospective long-term results.

Methods: From February 1985 to September 1998, 340 patients underwent simultaneous carotid endarterectomy and myocardial revascularization. The average age of the patients was 65.3 years; $45.6 \%$ were neurologically symptomatic, and $44.4 \%$ had bilateral carotid stenosis. The indication for carotid endarterectomy was lumen diameter reduction of more than $75 \%$, angiographic signs of thrombogenic endovascular morphology, or both. Carotid endarterectomy was performed in conjunction with cardiopulmonary bypass with mild hypothermia, hemodilution, systemic heparinization, and controlled hemodynamics under pulsatile perfusion for additional cerebral protection.

Results: There were 16 perioperative neurologic complications (4.7\%), 11 permanent deficits $(3.2 \%)$, and 9 cardiac complications $(2.6 \%)$. Early mortality was $2.6 \%$ (SE 0.8\%): 2 patients had a stroke and 2 had a myocardial infarction. The 5-year survival was $78.9 \%$ (SE 2.6\%), and freedom from ipsilateral stroke and cardiac event were 93.2\% (SE 1.5\%) and 87.5\% (SE $2.1 \%$ ), respectively. The predictor for early death was age over 70 years, and predictors for late death were age over 70 years, previous myocardial infarction, previous stroke, and bilateral carotid stenosis of greater than $90 \%$.

Conclusion: On the basis of our long-term results, we believe that simultaneous carotid endarterectomy and myocardial revascularization in conjunction with cardiopulmonary bypass is a method safe enough to prefer its routine use with acceptable low operative risk and satisfactory long-term morbidity. (J Thorac Cardiovasc Surg 2000;119:764-73)
P ostoperative cerebral stroke remains one of the most serious complications in cardiac surgery. The reported frequency of neurologic complications after coronary artery bypass grafting (CABG) varies widely, even in the more recent literature, depending on the sensitivity used to state postoperative neurologic changes.

From the Department of Thoracic and Cardiovascular Surgery, Heart Center North-Rhine Westfalia, Bad Oeynhausen, Germany.

Received for publication March 29, 1999; revisions requested May 27, 1999; revisions received Nov 12, 1999; accepted for publication Dec 7, 1999.

Address for reprints: Kazutomo Minami, MD, PhD, Department of Thoracic and Cardiovascular Surgery, Heart Center North-Rhine Westfalia, University of Bochum, Georgstrasse 11, D-32545 Bad Oeynhausen, Germany.

Copyright $\odot 2000$ by The American Association for Thoracic Surgery. 0022-5223/2000 $\$ 12.00+0 \quad \mathbf{1 2 / 1 / 1 0 4 8 7 9}$

doi:10.1067/mtc. 2000.104879
The frequency of severe perioperative neurologic complications in unselected patients undergoing CABG has been reported to be between $0.5 \%$ and $7.0 \% .^{1-3}$

Possible causes of neurologic complications after elective $\mathrm{CABG}$ include inadequate cerebral perfusion with hypotension or hypoperfusion, arterial macroembolization or microembolization, and intracranial or extracranial vascular disease. Because atherosclerosis is a generalized disease, a considerable number of patients have significant stenosis in both the coronary and carotid arteries. The incidence of significant stenosis of extracranial arteries in patients requiring $\mathrm{CABG}$ reported in the literature ranges from $2.4 \%$ to $14 \%$ and varies according to the diagnostic means used. - $6^{-6}$

Preexisting extracranial arterial occlusive disease is one of the most frequent causes of perioperative cerebral ischemia. The treatment strategy of patients with 


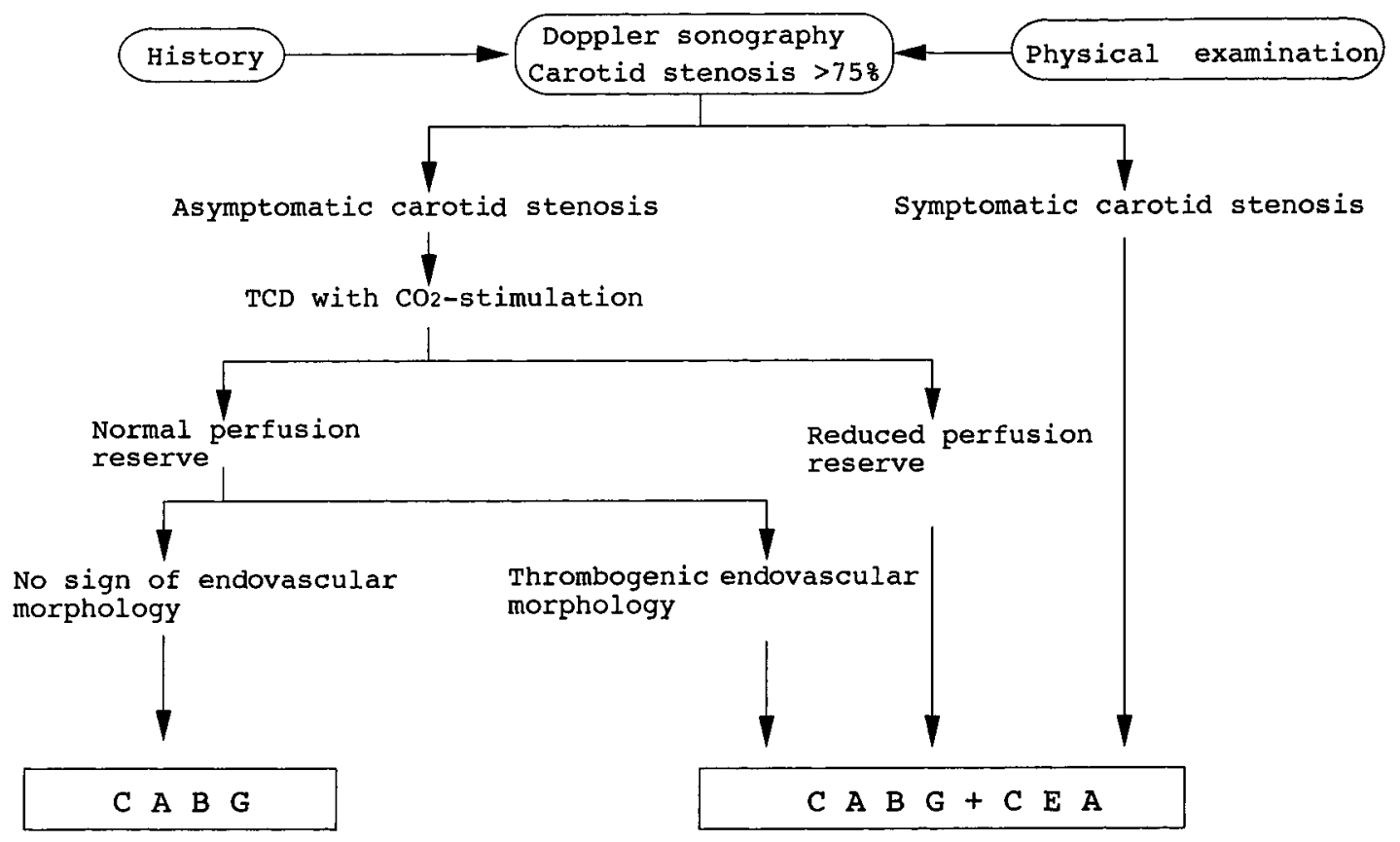

Fig 1. Our treatment strategy of patients with concominant occlusive disease of coronary and carotid arteries.

concomitant occlusive disease of coronary and carotid arteries is still a matter of discussion. Our operative strategy in these patients is to do simultaneous carotid artery endarterectomy and myocardial revascularization, with cardiopulmonary bypass $(\mathrm{CPB})$ being instituted before carotid endarterectomy for additional cerebral protection with mild hypothermia, hemodilution, systemic heparinization, and controlled hemodynamics under pulsatile perfusion.

In a previous publication in $1988,{ }^{7}$ we reported the initial experience with 47 patients who underwent simultaneous carotid endarterectomy and myocardial revascularization by using CPB for both procedures. In the actual report we describe our further experience with this operative strategy of concomitant occlusive disease of the coronary and carotid arteries and present its early and long-term results.

\section{Patients and methods}

From February 1985 until September 1998, 37,932 cardiac procedures with extracorporeal circulation were performed in our heart center. In $340(1.3 \%)$ of 26,607 consecutive CABG candidates, simultaneous revascularization of the carotid artery was carried out because of a relevant stenosis of one or both carotid arteries. The patients included 260 men (76.9\%) and 80 women (23.1\%) aged from 42.7 to 82.3 years (average, $65.3 \pm 7.3$ years).

In all CABG candidates particular attention was directed to their history of neurologic and cerebrovascular symptoms, and Doppler ultrasonographic examination was carried out. If
Doppler evaluation revealed a luminal reduction of more than $50 \%$ in the common or internal carotid artery, arterial digital subtraction angiography (alone or usually in combination with selective carotid cineangiography) was performed either simultaneously with cardiac catheterization or at a later date if the carotid stenosis initially had not been diagnosed. The initial indication for endarterectomy of the carotid artery was an angiographically diagnosed reduction in luminal diameter of more than $75 \%$, a sign of thrombogenic endovascular morphology (transitoric ischemic attack, minor stroke, or intimal ulcerations), or both. Since 1989, in case of asymptomatic carotid stenosis, transcranial Doppler ultrasonography (Neuroguard, Neuroguard Inc) was applied to indicate hemodynamic deterioration. ${ }^{8}$ A pathologic finding was defined as an increase of flow velocity in the mean cerebral artery of less than $20 \%$ after carbon dioxide stimulation induced by hypercapnia. ${ }^{9-11}$ Patients with reduced perfusion reserve were operated on regardless of whether carotid artery stenosis was symptomatic or not (Fig 1). Patients with asymptomatic carotid artery stenosis and normal perfusion reserve without ulcerations were treated with individual anticoagulation or antithrombogenic drugs, and ultrasonographic short-time interval follow-up was recommended.

Operative technique. All patients had a unilateral carotid endarterectomy with autologous saphenous vein patch plasty and concomitant CABG. All patients were operated on by the same surgeons. At first, the carotid artery was exposed. Then median sternotomy and cannulation were performed, and CPB was initiated to provide additional organ protection (mild hypothermia with a blood temperature of $27^{\circ} \mathrm{C}$, nasopharyngeal temperature of $30^{\circ} \mathrm{C}$, and hemodilution with 
Table I. Demographic and clinical characteristics

\begin{tabular}{lc}
\hline Characteristics & No. of patients (\%) \\
\hline Age (y) & \\
Mean \pm SD & $65.3 \pm 7.3$ \\
Range & $42.7-82.3$ \\
Sex & \\
Male & $260(76.9 \%)$ \\
Female & $80(23.1 \%)$ \\
Cardiac history & \\
Previous myocardial infarction & $140(41.2 \%)$ \\
Unstable angina & $43(12.6 \%)$ \\
Neurologic history & \\
Transient ischemic attack & $32(9.4 \%)$ \\
Amaurosis fugax & $27(7.9 \%)$ \\
PRIND & $54(15.9 \%)$ \\
Stroke & $43(12.6 \%)$ \\
Symptomatic carotid artery stenosis & $156(45.6 \%)$ \\
Other disease & \\
Arterial hypertension & $185(54.4 \%)$ \\
Diabetes mellitus & $89(26.7 \%)$ \\
Chronical obstructive lung disease & $53(15.6 \%)$ \\
Renal insufficiency & $27(7.9 \%)$ \\
\hline
\end{tabular}

PRIND, Prolonged reversible ischemic neurologic defect.

Table II. Angiographic data

\begin{tabular}{lc}
\hline Findings & No. of patients $(\%)$ \\
\hline Cardiac disease & \\
Left main stem stenosis & $33(9.7 \%)$ \\
Left ventricular ejection fraction $<40 \%$ & $81(23.8 \%)$ \\
Carotid artery disease & \\
Bilateral carotid artery stenosis & $151(44.4 \%)$ \\
Stenosis on operated side & \\
$<50 \%$ & $3(0.9 \%)$ \\
$50 \%-75 \%$ & $21(6.2 \%)$ \\
$75 \%-90 \%$ & $204(60.0 \%)$ \\
$90 \%-99 \%$ & $112(32.9 \%)$ \\
Contralateral stenosis & \\
$<50 \%$ & $216(63.5 \%)$ \\
$50 \%-75 \%$ & $48(14.1 \%)$ \\
$75 \%-90 \%$ & $31(9.1 \%)$ \\
$90 \%-99 \%$ & $10(2.9 \%)$ \\
$100 \%$ & $35(10.3 \%)$ \\
\hline
\end{tabular}

a hematocrit value of $20 \%$ to $25 \%$ ). In addition, a systemic mean arterial pressure of 60 to $70 \mathrm{~mm} \mathrm{Hg}$ with the unloaded beating heart was ensured by optimal manipulation of CPB, including synchronized pulsatile perfusion. Subsequently, endarterectomy and vein patch plasty of the carotid artery were done, and then CABG with intermittent myocardial ischemia was performed. The number of peripheral coronary anastomoses varied between 1 and 7, with an average of 2.9 \pm 1.0 . The neck incision was left open until the end of the cardiac procedure. Throughout the operation, the cerebral function was monitored by a continuous electroencephalogram (Drägerwerk AG). ${ }^{12}$ An intraluminal shunt was used in only a
Table III. Early postoperative complications and

\begin{tabular}{lc} 
events & \\
\hline Characteristics & No. of patients (\%) \\
\hline Early lethal complications & $9(2.6 \%)$ \\
Myocardial infarction & $2(0.6 \%)$ \\
Stroke & $2(0.6 \%)$ \\
Infection & $2(0.6 \%)$ \\
Multiple organ failure & $3(0.9 \%)$ \\
Early neurologic complications & $16(4.7 \%)$ \\
TIA/PRIND & $5(1.5 \%)$ \\
Ipsilateral stroke & \\
Minor & $5(1.5 \%)$ \\
Major & $3(0.9 \%)$ \\
Lethal & $1(0.3 \%)$ \\
Contralateral stroke & \\
Minor & 0 \\
Major & $1(0.3 \%)$ \\
Lethal & $1(0.3 \%)$ \\
Early cardiac complications & \\
Myocardial infarction & $2(0.6 \%)$ \\
Ventricular arrhythmia & $5(1.5 \%)$ \\
Low-output syndrome & $2(0.6 \%)$
\end{tabular}

TIA, Transient ischemic attack; PRIND, prolonged reversible ischemic neurologic defect.

few patients who had a sign of cerebral ischemia with the electroencephalogram monitor.

The preoperative clinical characteristics of the patients are shown in Table I, and the angiographic features of the patient population are listed in Table II. The criteria for stating a perioperative myocardial infarction are the occurrence of new Q waves and persistent ST-segment changes correlated with an elevated myocardial fraction of creatinine kinase (CK-MB > $50 \mathrm{U} / \mathrm{L}$ ). In later years, cardiac troponin $\mathrm{T}$ was used to state perioperative myocardial infarction (troponin $\mathrm{T}>0.5 \mu \mathrm{g} / \mathrm{L}$ ).

Statistical analysis. Preoperative and perioperative data were obtained by reviewing the patient's hospital records, and information on long-term survival or events was gained by questionnaires to the patient's referring physician and cardiologist. Data are expressed as mean \pm SD. Early death and early stroke (with persisting neurologic deficit) were defined as events within 30 days postoperatively. For time-independent risk factor analysis (early postoperative events), the 2tailed Fisher exact test and $t$ test were used. Time-dependent factors were analyzed by the Kaplan-Meier method, the logrank test, the Pearson correlation, and Cox regression models. Freedom-from-event percentages are given with SEs. Calculations were made with SPSS Release 8.0.0 (SPSS Inc).

\section{Results}

Patients were traced for a mean follow-up of $5.28 \pm$ 3.8 years; total follow-up time is 1759 patient-years. Follow-up is $98.8 \%$ complete.

Early mortality after simultaneous carotid endarterectomy and coronary revascularization was $2.6 \%$ (9 patients). There was a clear association between early death and age over 70 years $(P=.02)$. 


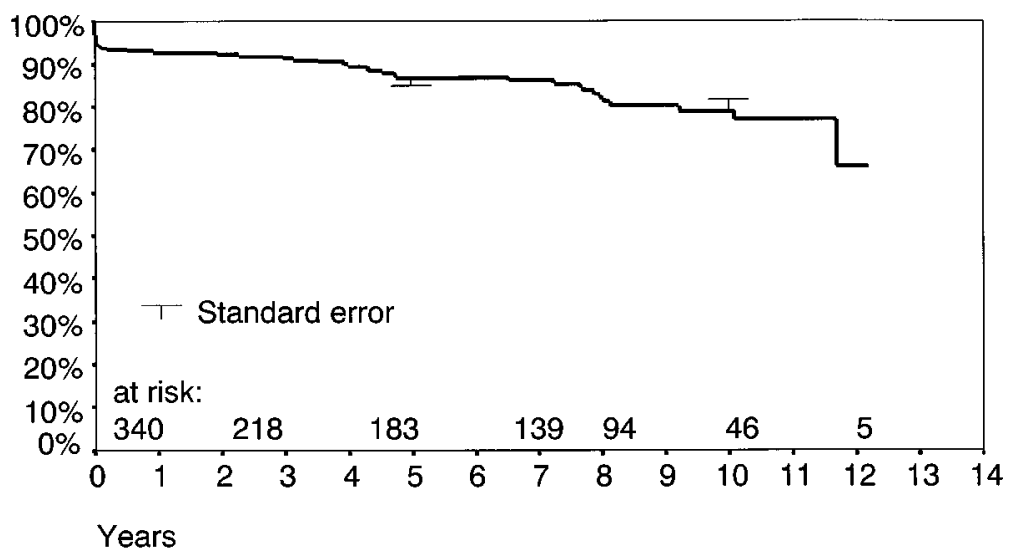

Fig 2. Freedom from overall stroke.

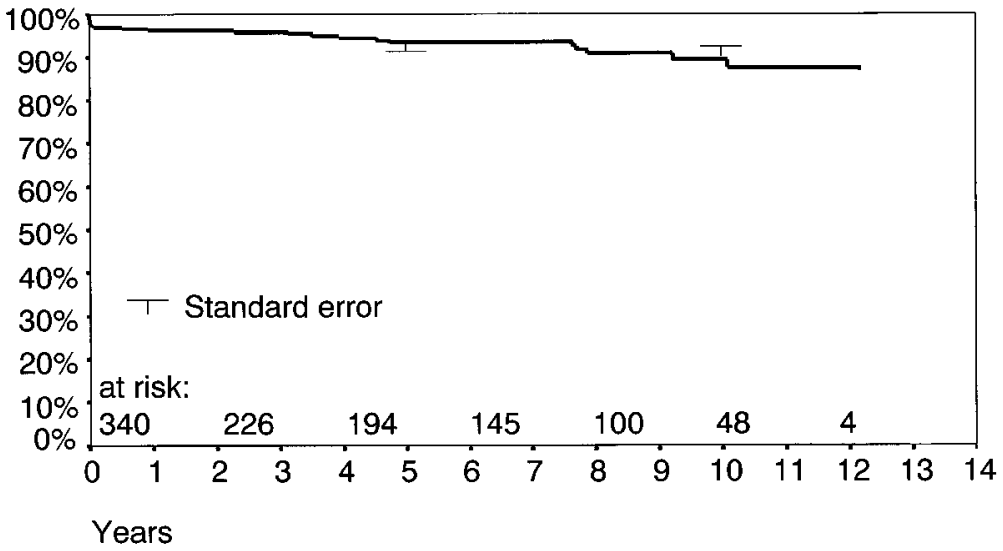

Fig 3. Freedom from ipsilateral stroke.

Table IV. Risk factors for early death and stroke

\begin{tabular}{|c|c|c|c|c|c|c|}
\hline \multirow[b]{2}{*}{ Event } & \multirow[b]{2}{*}{ Factor } & \multicolumn{2}{|c|}{ Factor present } & \multirow[b]{2}{*}{ P value* } & \multicolumn{2}{|c|}{ Factor absent } \\
\hline & & $\begin{array}{c}\text { Patients } \\
\text { without events }\end{array}$ & $\begin{array}{c}\text { Patients } \\
\text { with events }\end{array}$ & & $\begin{array}{c}\text { Patients } \\
\text { without events }\end{array}$ & $\begin{array}{c}\text { Patients } \\
\text { with events }\end{array}$ \\
\hline Early death & Age $>70 y$ & 90 & $6(6.7 \%)$ & .016 & 241 & $3(1.2 \%)$ \\
\hline Early stroke & Previous stroke & 49 & $6(12.2 \%)$ & .026 & 275 & $10(3.6 \%)$ \\
\hline
\end{tabular}

*Fisher exact test.

Perioperative neurologic complications were seen in 16 patients $(4.7 \%)$, including 11 permanent deficits $(3.2 \%)$.

Early cardiac complications were 2 lethal myocardial infarctions. In 5 patients we saw drug-responsive ventricular arrhythmias, and 2 patients had transient low-output syndrome (Table III). The significant univariate risk factors for early death and stroke are listed in Table IV.

Late neurologic events occurred in 29 patients, including 10 lethal strokes. The ipsilateral side was dominant for early stroke (ipsilateral side, $\mathrm{n}=7$; contralateral side, $n=4$ ), but late stroke occurred more often on the contralateral side (ipsilateral side, $\mathrm{n}=12$; contralateral side, $\mathrm{n}=17$ ). Ten-year incidences of stroke were $9.3 \%$ (SE 2.5\%) on the ipsilateral side and $11.8 \%$ (SE 2.6\%) on the contralateral side. Overall freedom from stroke (Fig 2) at 5 years and 10 years was 86.8\% (SE 2.1\%) and 78.9\% (SE 3.2\%), and freedom from ipsilateral stroke (Fig 3) was 93.2\% (1.6\%) and $89.3 \%$ (SE 2.5\%). 


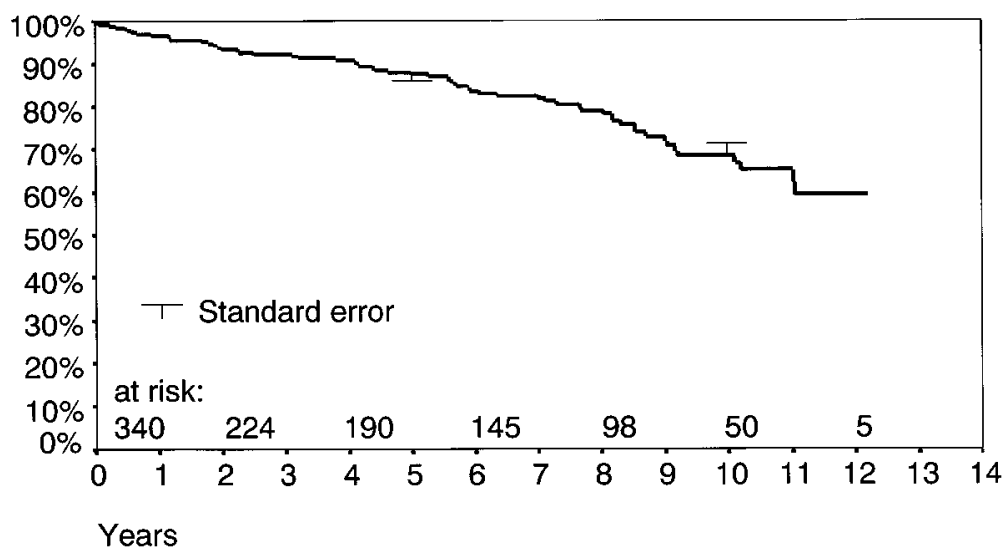

Fig 4. Freedom from cardiac events.

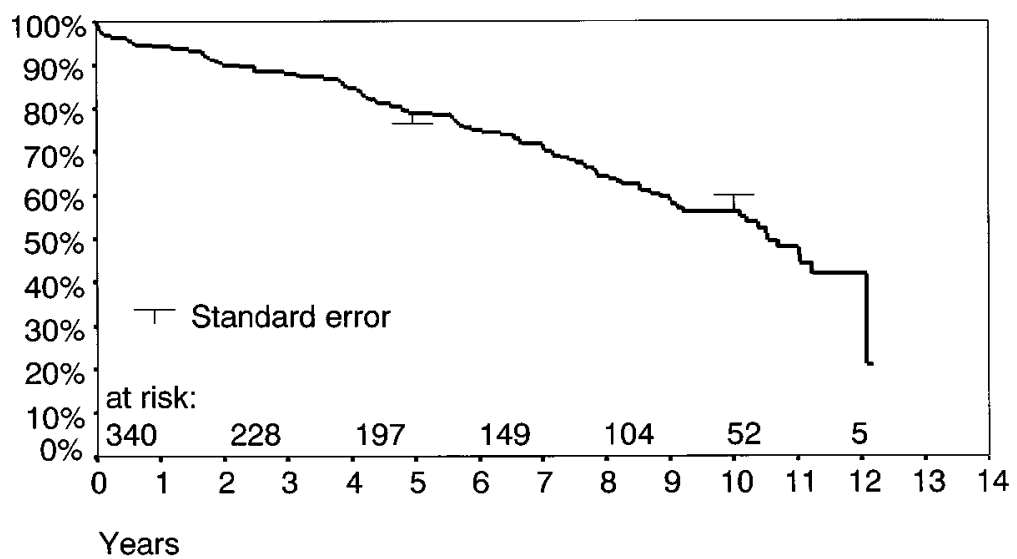

Fig 5. Overall actuarial survivals.

Late cardiac events occurred in 62 patients, including 27 lethal cardiac failures and 16 sudden deaths. Freedom from cardiac event (Fig 4) was 87.5\% (SE 2.1\%) and $68.3 \%$ (SE $3.4 \%$ ) at 5 and 10 years, respectively.

Actuarial survival (Fig 5) was 78.9\% (SE 2.6\%) and $56.1 \%$ (SE 3.7\%) at 5 and 10 years, respectively. Causes of late death were cardiac events in 52 patients (9 patients with cardiac infarction, 27 patients with cardiac failure, and 16 patients with sudden death), stroke in 10 patients, carcinoma in 18 patients, unknown causes in 8 patients, and other causes in 26 patients. Univariate risk factors of late death were age over 70 years, previous myocardial infarction, previous stroke, and bilateral carotid stenosis over $90 \%$. Risk factors for late death, stroke, and neurologic or cardiac events are listed in Table V. The results of multivariate analysis for time-dependent risk factors are listed in Table VI.

\section{Discussion}

Perioperative stroke after myocardial revascularization is an issue of increasing importance to cardiac surgeons. Patients with neurologic symptomatic carotid artery stenosis and a history of stroke undergoing $\mathrm{CABG}$ are at a higher risk of perioperative stroke than CABG candidates with asymptomatic carotid artery stenosis. Jones and associates ${ }^{13}$ noted an $8.6 \%$ incidence of perioperative stroke in patients with prior neurologic symptoms undergoing $\mathrm{CABG}$. In our institution between February 1985 and September 1998, CABG was performed in 26,607 patients, and the incidence of perioperative neurologic complications was $3.1 \%$, including $1.2 \%$ neurologic deficit. ${ }^{14}$

The reported incidence of significant carotid artery stenosis in candidates for CABG varies from $1.6 \%$ to $6.8 \%{ }^{4-6}$ A retrospective study of our own data ${ }^{14}$ (5880 
Table V. Univariate analysis of risk factors for late events

\begin{tabular}{|c|c|c|c|c|c|c|c|}
\hline \multirow[b]{3}{*}{ Event } & \multirow[b]{3}{*}{ Factor } & \multirow[b]{3}{*}{$n$} & \multicolumn{5}{|c|}{ Percentage of freedom from event (SE) } \\
\hline & & & \multicolumn{2}{|c|}{ Factor present } & \multirow[b]{2}{*}{$\mathrm{P}$ value } & \multicolumn{2}{|c|}{ Factor absent } \\
\hline & & & $5 y$ & $10 y$ & & $5 y$ & $10 y$ \\
\hline \multicolumn{8}{|c|}{ Late death } \\
\hline & Bilateral carotid stenosis $>90 \%$ & 14 & $30.3(16.6)$ & 0 & .001 & $80.1(2.5)$ & $58.0(3.7)$ \\
\hline & Previous myocardial infarction & 139 & $75.5(4.2)$ & $44.7(5.8)$ & .013 & $81.5(3.2)$ & $65.1(4.7)$ \\
\hline & Age $>70 y$ & 93 & $71.4(5.6)$ & $45.5(7.7)$ & .025 & $81.7(2.8)$ & $59.6(4.2)$ \\
\hline & Previous stroke & 52 & $66.7(8.1)$ & $40.3(9.9)$ & .044 & $80.9(2.7)$ & $59.1(3.9)$ \\
\hline \multicolumn{8}{|c|}{ Late stroke } \\
\hline & Previous cardiac operation & 16 & $56.3(20.9)$ & 0 & .032 & $93.6(1.8)$ & $83.0(3.4)$ \\
\hline \multicolumn{8}{|c|}{ Cerebral or cardiac event } \\
\hline & Bilateral carotid stenosis $>90 \%$ & 14 & $39.0(16.9)$ & 0 & .003 & $77.1(2.7)$ & 0 \\
\hline & Previous myocardial infarction & 139 & $74.9(4.2)$ & $44.7(8.5)$ & .008 & $76.4(3.5)$ & $62.3(5.1)$ \\
\hline & Symptomatic carotid stenosis & 80 & $65.3(6.6)$ & $39.3(8.5)$ & .035 & $78.5(2.9)$ & $58.8(4.4)$ \\
\hline & Previous stroke & 52 & $65.2(7.9)$ & $37.0(10.3)$ & .099 & $77.5(2.8)$ & $57.7(4.2)$ \\
\hline
\end{tabular}

Table VI. Multivariate analysis of time-dependent risk factors

\begin{tabular}{|c|c|c|c|c|c|c|}
\hline Events & Factor & $\beta$ & $S E$ & $\mathrm{P}$ value & $H R$ & $95 \% C I$ \\
\hline \multicolumn{7}{|c|}{ Late death } \\
\hline & Bilateral carotid stenosis $>90 \%$ & -1.14 & 0.40 & .005 & 0.32 & $0.14-0.71$ \\
\hline & Previous myocardial infarction & 0.46 & 0.20 & .023 & 1.58 & $1.07-2.35$ \\
\hline & Age $>70 y$ & 0.46 & 0.22 & .031 & 1.59 & $1.04-2.43$ \\
\hline & Previous stroke & 0.51 & 0.25 & .040 & 1.67 & $1.02-2.73$ \\
\hline \multicolumn{7}{|c|}{ Cerebral or cardiac event } \\
\hline & Bilateral carotid stenosis $>90 \%$ & -1.29 & 0.40 & .001 & 0.27 & $0.12-0.61$ \\
\hline & Symptomatic carotid stenosis & -1.2 & 0.44 & .006 & 0.30 & $0.13-0.59$ \\
\hline & Previous stroke & 0.54 & 0.26 & .042 & 1.71 & $0.98-2.29$ \\
\hline & Previous myocardial infarction & 0.41 & 0.21 & $.056^{*}$ & 1.50 & $0.99-2.29$ \\
\hline
\end{tabular}

$H R$, Hazards ratio; $C I$, confidence interval.

*Not significant.

consecutive patients with $\mathrm{CABG}$ ) showed significant coexistent occlusive disease of the carotid artery in $2.4 \%$. The number of candidates for surgery of concomitant occlusive disease of coronary and carotid artery is increasing. Tuman and associates ${ }^{15}$ reported that patients younger than 65 years who underwent CABG had an incidence of stroke of $0.9 \%$, whereas asymptomatic patients older than 75 years had an incidence of stroke of $8.9 \%$, and the incidence of stroke rose with increasing age.

Because of the rising number of elderly patients requiring cardiac surgery, it became more important to evaluate latent stenoses of carotid arteries. However, sometimes there are relevant discrepancies between Doppler ultrasonographic and angiographic findings. Moreover, in our opinion, even if digital subtraction angiography seems to be a useful general screening method in providing information about the overall status of the extracranial arteries, it is not accurate enough to plan an operation. Therefore we insisted on a selective carotid angiography to evaluate the morphology of the carotid lesion before operation. Recently, we also used transcranial Doppler ultrasonography with carbon dioxide stimulation as an effective preoperative diagnostic method. ${ }^{8}$ We decided to perform carotid endarterectomy in patients with neurologically asymptomatic carotid stenosis if the perfusion reserve measured by using transcranial Doppler ultrasonography is reduced more than $20 \%$ below the normal value. ${ }^{9-11}$

There is a continuing controversy about the management of patients with concomitant occlusive disease of the coronary and carotid arteries. In previous studies some groups have preferred to perform an isolated CABG, even in patients with hemodynamically relevant carotid artery stenosis, whereas others perform carotid thromboendarterectomy before CABG (2-stage procedure). However, experience with CABG without surgical treatment of hemodynamically relevant carotid 
artery stenosis indicates that the rate of perioperative neurologic complications after this policy is between $7.4 \%$ and $20.3 \%$, with a mortality between $6.9 \%$ and $13.8 \% \cdot{ }^{13,16-19}$ On the other hand, when an isolated carotid artery endarterectomy is performed before necessary CABG, the morbidity is relatively high (around $7 \%-8 \%$ ) and is caused mainly by myocardial infarction. ${ }^{16}$ Therefore some authors advocate the 1-stage procedure (combined surgery, carotid thromboendarterectomy before insertion of $\mathrm{CPB}$ for $\mathrm{CABG}$ or simultaneous surgery, and carotid endarterectomy under $\mathrm{CPB}$ before $\mathrm{CABG}$ ). They recommended this 1-stage procedure if unstable angina pectoris, left main stem coronary artery stenosis, or diffuse multivessel coronary artery disease coexisting with symptomatic carotid artery occlusive disease is present. ${ }^{13,16,19,20}$ Mehigan and associates ${ }^{17}$ prefer the 2 -stage procedure if the clinical situation allows it and the 1-stage operation in poorrisk candidates. A staged approach is reserved by some authors for patients with severe carotid artery stenosis, complicated carotid revascularization, or significant bilateral carotid disease with relatively less severe coronary artery disease. ${ }^{13,16}$ In recent studies Akins and colleagues $^{21}$ and Trachiotis and Pfister, ${ }^{22}$ who performed combined carotid endarterectomy and CABG, recommended 1-stage operation as the most effective means of avoiding myocardial complications and reducing neurologic deficits. In a meta-analysis on reports for surgical treatment of concomitant carotid and coronary artery disease, Takach and coworkers ${ }^{23}$ summarized the combined procedure to be as safe as the staged procedure despite the higher-risk population in the combined procedure.

In the 1-stage procedure most authors repair the carotid artery stenosis before full establishment of CPB. In contrast, we prefer to use the advantages of $\mathrm{CPB}$, such as hemodilution, hypothermia, heparinization, and hemodynamic control, for cerebral protection during carotid endarterectomy. Hypothermia induced by moderate systemic blood cooling around $27^{\circ} \mathrm{C}$ during $\mathrm{CPB}$ can be expected to protect the brain by decreasing cerebral oxygen consumption and to decrease the accumulation of anoxic metabolites in brain tissue. We keep the nasopharyngeal temperature at around $30^{\circ} \mathrm{C}$, maintaining a beating heart for pulsatile body perfusion. Although there is a lack of consensus concerning the optimal mean arterial pressure for cerebral protection during $\mathrm{CPB}$, higher perfusion pressures of 70 to $90 \mathrm{~mm} \mathrm{Hg}$ are considered to be safer in patients with occlusive disease of the carotid artery. Tufo and coworkers ${ }^{24}$ found that lowering of systemic arterial blood pressure below $50 \mathrm{~mm} \mathrm{Hg}$ for longer than 10 minutes resulted in a 4-fold increase in risk compared with that observed when higher blood pressure was present. In a recent review of concomitant disease of the carotid and coronary arteries, Lazar and Menzoian ${ }^{25}$ concluded that neurologic complications of CPB appear to be more related to arteriosclerotic aortic disease than to low flow caused by carotid artery stenosis.

In this context, however, disadvantages of performing carotid endarterectomy under CPB, such as excessive operative bleeding, prolonged operation time, and possible blood contamination of the drapes around the carotid incision, might lead to a higher incidence of mediastinal infection. Although there are 2 lethal infections $(0.6 \%)$ in our series, the incidence of mediastinal infection was not higher than that of elective isolated CABG in our institution. On the other hand, there are some advantages in the 1-stage approach, including shorter hospital stay, decreased exposure to anesthesia, and cost savings. ${ }^{26}$

Hypothermia was expected to make the analysis of electroencephalography more difficult than in isolated carotid endarterectomy under normothermia. In our series minor electroencephalographic changes were fairly common during carotid endarterectomy, but they were generally not followed by cerebral sequelae. In contrast, most of the electroencephalographic changes that occurred after carotid endarterectomy were associated with perioperative neurologic complications. $^{7}$ This suggests that cerebral embolism might be a frequent cause of postoperative cerebral deficits.

Our early and long-term results suggest that elderly patients have an elevated risk for early and late death. Strategy of treatment and strategy of operative management of such elderly patients must be considered thoughtfully. The results in this series, particularly the excellent freedom from neurologic events in the early and long-term course, support the efficiency of our simultaneous operative strategy. The operative mortality and the incidence of neurologic complications and myocardial infarction in this report compare favorably with literature data for patients with concomitant severe occlusive disease of the coronary and carotid arteries managed by using a combined operative approach (Table VII). ${ }^{23,27-31}$

On the basis of our long-term results, we believe that simultaneous carotid endarterectomy and myocardial revascularization both in conjunction with $\mathrm{CPB}$ is a method safe enough to prefer its routine use with acceptable low operative risk and satisfactory longterm morbidity. 
Table VII. Review of the results after combined operative approach

\begin{tabular}{|c|c|c|c|c|c|}
\hline First author & Year & No. of patients & $\begin{array}{l}\text { Neurologic } \\
\text { deficit (\%) }\end{array}$ & $\begin{array}{c}\text { Myocardial } \\
\text { infarction (\%) }\end{array}$ & Death (\%) \\
\hline \multicolumn{6}{|c|}{$\mathrm{CEA}$ without $\mathrm{CPB}$} \\
\hline Hertzer $^{27}$ & 1989 & 170 & 5.3 & - & 5.3 \\
\hline Vermeulen $^{28}$ & 1992 & 230 & 3.0 & 1.8 & 3.5 \\
\hline $\operatorname{Rizzo}^{29}$ & 1992 & 127 & 5.5 & 4.7 & 5.5 \\
\hline Akins $^{21}$ & 1995 & 200 & 3.0 & 2.5 & 3.5 \\
\hline Mackey $^{30}$ & 1996 & 100 & 9.0 & 6.0 & 8.0 \\
\hline Daily $^{26}$ & 1996 & 100 & 0 & 1.0 & 4.0 \\
\hline Darling $^{31}$ & 1998 & 420 & 1.2 & 0.2 & 2.4 \\
\hline \multicolumn{6}{|l|}{ CEA with $\mathrm{CPB}$} \\
\hline Our results & 1999 & 340 & 3.2 & 0.6 & 2.6 \\
\hline
\end{tabular}

$C E A$, Carotid artery endarterectomy: $C P B$, cardiopulmonary bypass.

\section{REFERENCES}

1. Kartchner MM, McRae LP. Carotid occlusive disease as a risk factor in major cardiovascular surgery. Arch Surg 1982;117: 1086-8.

2. Rodewald G, Dahme B, Emskotter T, Lachenmeyer L, Lamparter U, Kalmar P, et al. Central nervous system risk factors in heart surgery. Z Kardiol 1990;79:13-21.

3. Egloff L, Laske A, Siebemann R, Studer M, Keller H. Cerebral insult in heart surgery. Schweiz Med Wochenschr 1996;126:47782.

4. Bull DA, Neumayer LA, Hunter GC, Keksz J, Sethi GK, Mclntyre KE, et al. Risk factors for stroke in patients undergoing coronary artery bypass grafting. Cardiovasc Surg 1993;1:182-5.

5. Swain JA. Cardiac surgery and brain. N Engl J Med 1993;329: 1119-20.

6. Ricotta JJ, Faggioli GL, Castilone A, Hassett JM. Risk factors for stroke after cardiac surgery. Buffalo Cardiac-Cerebral Study Group. J Vasc Surg 1995;21:359-63.

7. Minami K, Sagoo KS, Breymann T, Fassbender D, Schwerdt M, Koerfer R. Operative strategy in combined coronary and carotid artery disease. J Thorac Cardiovasc Surg 1988;95:303-9.

8. Minami K, Damsch R, Inoue K, Körfer R. Assessment of cerebral perfusion reserve in patients with severe carotid and coronary artery disease by transcranial Doppler sonography: diagnostic and therapeutical consequence. Z Herz- Thorax- Gefäßchir 1991;5:17-22.

9. Aaslid R, Markwalder T, Nornes H. Noninvasive transcranial Doppler ultrasound recording of flow velocity in basal cerebral arteries. J Neurosurg 1982;57:769-74.

10. Bischop CCR, Powell S, Insall M, Rutt D. Effect of internal carotid artery occlusion on cerebral artery blood flow at rest in response to hypercapnia. Lancet 1986;29:710-2.

11. Ringelstein EB, Grosse W, Matentzoglu S, Göckner WM. Noninvasive assessment of the cerebral vasomotor reactivity by means of transcranial Doppler sonography during hyper- and hypocapnea. Klin Wochenschr 1986;64:194-5.

12. Inoue K, Minami K, Hartmann N, Dallmann G, Reichelt W. EEG and cerebral complications in combined carotid and cardiac operations. J Cardiothorac Anesth 1989;3(Suppl 1):73.

13. Jones EL, Craver JM, Michalik RA, Murphy DA, Guyton RA, Bone DK, et al. Combined carotid and coronary operation: When are they necessary? J Thorac Cardiovasc Surg 1984;87:7-16.
14. Inoue K, Lüth LU, Pottkämper D, Strauß KM, Minami K, Reichelt W. Incidence and risk factors of perioperative cerebral complications: heart transplantation compared to coronary artery bypass grafting and valved surgery. J Cardiovasc Surg 1998;39: 201-8.

15. Tuman KJ, McCarthy RJ, Najafi H, Ivankovich AD. Differential effects of advanced age on neurologic and cardiac risks of coronary artery operations. J Thorac Cardiovasc Surg 1992;104:1510-7.

16. Hertzer NR, Loop FD, Taylor PC, Beven EG. Staged and combined surgical approach to simultaneous carotid and coronary vascular disease. Surgery 1978;84:803-11.

17. Mehigan JT, Buch WS, Pipkin RD, Fogarty TJ. A planned approach coexistent cerebrovascular disease in coronary artery bypass candidates. Arch Surg 1997;112:1403-9.

18. Schwartz RL, Garrett JR, Karp RB, Kouchoukos NT. Simultaneous myocardial revascularization and carotid endarterectomy. Circulation 1982;66:97-101.

19. Reul GJ, Morris GC, Howell JF, Grawford ES, Stelter WY. Current concepts in coronary artery surgery: a critical analysis of 1,287 patients. Ann Thorac Surg 1972;14:243-57.

20. Ennix CL Jr, Lawrie GM, Morris GC Jr, Crawford ES, Howell JF, Reardon MJ, at al. Improved results of carotid endarterctomy in patients with symptomatic coronary disease: an analysis of 1,546 consecutive carotid operations. Stroke 1979;10:122-5.

21. Akins CW, Moncure AC, Daggett WM, Cambria RP, Hilgenberg AD, Torchiana DF, et al. Safety and efficacy of concomitant carotid and coronary artery operations. Ann Thorac Surg 1995; 60:331-8.

22. Trachiotis GD, Pfister AJ. Management strategy for simultaneous carotid endarterectomy and coronary revascularization. Ann Thorac Surg 1997;64:1013-8.

23. Takach TJ, Reul GJ, Cooley DA, Duncan JM, Ott DA, Livesay JJ, et al. Is an integrated approach warranted for concomitant carotid and coronary artery disease? Ann Thorac Surg 1997;64:16-22.

24. Tufo HN, Ostfeld AM, Shebelle RE. Central nervous system dysfunction following open-heart surgery. JAMA 1970;212:1333-40.

25. Lazar HL, Menzoian JO. Coronary artery bypass grafting in patients with cerebrovascular disease. Ann Thorac Surg 1998; 66:968-74.

26. Daily PO, Freeman RK, Dembitsky WP, Adamson RM, MorenoCabral RJ, Marcus S, et al. Cost reduction by combined carotid endarterectomy and coronary artery bypass grafting. J Thorac Cardiovasc Surg 1996;111:1185-93. 
27. Hertzer NR, Loop FD, Beven EG, O'Hara PJ, Krajewski LP. Surgical staging for simultaneous coronary and carotid disease: a study including prospective randomization. J Vasc Surg 1989;9: 455-63.

28. Vermeulen FEE, Hamerlijnck RPHM, Defauw JJAM, Ernst SMPG. Synchronous operation for ischemic cardiac and cerebrovascular disease: early results and long-term follow-up. Ann Thorac Surg 1992;53:381-90.

29. Rizzo RJ, Whittemore AD, Couper GS, Donaldson MC, Aranki SF, Collins JJ Jr, et al. Combined carotid and coronary revascularization: the preferred approach to the severe vasculopath. Ann Thorac Surg 1992;54:1099-109.

30. Mackey WC, Khabbaz K, Boiar R, O’Donnell TF Jr. Simultaneous carotid endarterectomy and coronary bypass: perioperative risk and long-term survival. J Vasc Surg 1996;24:58-64.

31. Darling RC, Dylewski M, Chang BB, Paty PSK, Kreienberg PB, Lloyd WE, et al. Combined carotid endarterectomy and coronary bypass grafting does not increase the risk of perioperative stroke. Cardiovasc Surg 1998;6:448-52.

\section{Appendix}

Analyzed potential risk factors
Age
Diabetes
Obesity
Hyperlipidemia
Hypertension
Smoking
Previous lung disease
Symptomatic carotid stenosis
Previous stroke
Previous transient ischemic attack
Previous peripheral atherosclerotic occlusive disease
Previous carotid operation
Bilateral carotid stenosis
Severity of ipsilateral-contralateral carotid stenosis
Previous myocardial infarction
Previous cardiac decompensation
Previous cardiac operation
Number of diseased coronary vessels
Number of CABGs
Concomitant valve operation

\section{Commentary}

Currently there is growing appreciation among many cardiac surgeons that patients with severe concomitant carotid and coronary artery disease are better treated with combined myocardial revascularization and carotid endarterectomy during one period of anesthesia. Given that decision, several surgical approaches have been suggested for technically performing the combined operation. In the majority of institutions the carotid endarterectomy is performed while the heart is still beating before the institution of cardiopulmonary bypass (CPB). In 1977 Reis and Hannah ${ }^{1}$ advocated performance of the carotid endarterectomy during $\mathrm{CPB}$ with significant hypothermia. Several reports with small numbers of patients have documented the results achieved with such an approach. ${ }^{1-4}$ Schwartz and associates $^{2}$ compared patients having carotid endarterectomy before CPB with patients having carotid endarterectomy during $\mathrm{CPB}$ and could find no advantage to the latter technique.

In this issue of the Journal, Minami and coworkers report their early and late results with simultaneous carotid endarterectomy and coronary artery bypass grafting (CABG) during CPB in 340 patients. Minami and colleagues advocate a technique that entailed initial exposure of the carotid artery followed by a median sternotomy and institution of CPB at a blood temperature of $27^{\circ} \mathrm{C}$. With the unloaded heart beating on $\mathrm{CPB}$, the carotid endarterectomy was completed with the use of a vein patch. Myocardial revascularization was then performed during intermittent aortic crossclamping with an average of 2.9 grafts per patient. The neck incision was closed at the end of the procedure.

Cerebral function was monitored throughout the operation with continuous electroencephalography. Intraluminal shunts were used only in patients in whom the electroencephalograph demonstrated cerebral ischemia.

In this current series the early mortality rate of $2.6 \%$ and the neurologic complication rate of $4.7 \%$ (permanent deficits in $3.2 \%$ ) are certainly comparable, as noted in the article, with early results reported from series in which the carotid endarterectomy was performed before CPB. Although the acuity of the patients' ischemic disease is not specifically described in the study, the complexity of the preoperative carotid evaluation, the relatively lower number of arteries revascularized, and the absence of ischemic acuity as a predictor of hospital mortality suggest that most of these patients were probably undergoing elective myocardial revascularization. The low mortality is probably in part a function of the younger age of the patients and the absence of acute ischemia with lesser degrees of coronary disease, as well as excellent technique by the authors. The low incidence of stroke can also be answered in part by less extensive generalized atherosclerosis in younger patients, particularly since their technique of myocardial preservation requires repeated applications of an aortic crossclamp, and most of the early strokes were ipsilateral to the carotid endarterectomy.

The long-term survival of $56.1 \%$ at 10 years is comparable with results from other series with patients of similar ages, and the late freedom from neurologic events of $78.9 \%$ at 10 years is somewhat lower than the $92.3 \%$ that my colleagues and $\mathrm{I}^{5}$ reported several years ago. 
Although the authors are to be commended for their excellent results, several questions arise concerning this approach. The first centers on the physiologic rationale for the authors' technique. Certainly systemic hypothermia to a blood temperature of $27^{\circ} \mathrm{C}$ will be neuroprotective to some extent for modest periods of time. Weiss and coworkers ${ }^{4}$ strongly advised using hypothermia to much lower levels, specifically, $20^{\circ} \mathrm{C}$. The neuroprotective effect of hypothermia is probably useful in ameliorating the potential negative effects of several other aspects of their technique; for example, the loss of true pulsatile perfusion on CPB. The authors state that the heart is unloaded during CPB and, therefore, the normal pulsatile pattern must be blunted. In addition, hypothermia in combination with anesthetic agents routinely produces generalized slowing of the electroencephalogram, which can mask cerebral ischemia that would normally also be revealed as slowing on the electroencephalogram. Thus the decision to place an intraluminal shunt may be delayed. Obviously, hypothermia would not completely mask asymmetric, lateralized slowing, but it might delay the recognition of its presentation. Their claim that hemodilution during CPB is also advantageous to cerebral protection is more difficult to understand.

Another question that arises concerning the authors' approach is whether there is a disadvantage to prolonging CPB to perform the carotid endarterectomy. Cardiac surgeons attempt to keep any period of CPB as short as is practical to safely complete the intended operation. Longer perfusion times cannot be an advantage. In this series there were only 2.9 coronary anastomoses per patient, a relatively low number compared with most series. CPB times for that portion of the operation should, therefore, be relatively short; thus the addition of the time to perform the carotid endarterectomy might be relatively less injurious.

Another feature of the authors' CPB technique that deserves comment is the degree of hypothermia that they use, namely, $27^{\circ} \mathrm{C}$. Although the lower the temperature, the greater the general neuroprotective effect, this temperature is lower than many cardiac surgeons currently use to perform myocardial revascularization. Whether the added time to cool and rewarm or any potential deleterious effects of deeper hypothermia might have an impact on the results is unclear.

Our own experience with performing carotid endarterectomy before myocardial revascularization during CPB now extends to almost 500 patients. The average age of our patients approaches 70 years, and the average number of CABGs is about 4 per patient. Our mortality and neurologic results are comparable with those reported by the authors in similar patients. Although we believe we have almost neutralized carotid stenosis as a risk factor for ipsilateral stroke during myocardial revascularization, our principal neurologic problem now is the occurrence of contralateral or bilateral deficits in patients with extensive aortic atherosclerosis. Advanced patient age and acute ischemic coronary syndromes necessitating nonelective operations remain the strongest predictors of early mortality.

In summary, the operative approach to concomitant carotid and coronary disease of performing both revascularization procedures on CPB has achieved very good results in the authors' hands in their patient population. Whether this approach is equally applicable to older patients with more acute ischemia and with more extensive coronary and aortic atherosclerosis remains to be demonstrated.

Cary W. Akins, MD Boston, Massachusetts

\section{REFERENCES}

1. Reis RL, Hannah H 3d. Management of patients with severe coexistent coronary artery and peripheral vascular disease. J Thorac Cardiovasc Surg 1977;73:909-18.

2. Schwartz RL, Garrett JR, Karp RB, Kouchoukos NT. Simultaneous myocardial revascularization and coronary endarterectomy. Circulation 1982;66(Suppl):I-97-101.

3. Matar AF. Concomitant coronary and cerebral revascularization under cardiopulmonary bypass. Ann Thorac Surg 1986;41:431-5.

4. Weiss SJ, Sutter FP, Shannon TO, Goldman SM. Combined cardiac operation and carotid endarterectomy during aortic crossclamping. Ann Thorac Surg 1992;53:813-6.

5. Akins CW, Moncure AC, Daggett WM, et al. Safety and efficacy of concomitant carotid and coronary artery operations. Ann Thorac Surg 1995;60:311-8. 